Caring : Jurnal Keperawatan

Vol.8, No. 1, Maret 2019, pp. $09-14$

ISSN 1978-5755 (Online)

DOI: 10.29238

Journal homepage: http://e-journal.poltekkesjogja.ac.id/index.php/caring/

\title{
Hubungan dukungan instrumental dengan beban pada anggota keluarga skizofrenia di Poliklinik Keperawatan Jiwa RSJ Grhasia Provinsi DIY
}

\section{The correlation between instrumental support and burden of family members among schizophrenia patients at Mental Treatment Polyclinic Of Grhasia Mental Hospital, Yogyakarta Special Province}

\author{
Rohana Fatma Zahra ${ }^{1}$, Sutejo ${ }^{2}$ \\ ${ }^{1}$ Prodi IImu Keperawatan FKIK Universitas Muhammadiyah Yogyakarta \\ 2 Program Studi Ilmu Keperawatan Poltekkes Kemenkes Yogyakarta
}

\section{HIGHLIGHTS}

\section{ARTICLE INFO}

\section{Article history}

\section{Keywords:}

Instrumental support

Family burden

Schizophrenia

Family

\section{Kata kunci:}

Dukungan Instrumental

Beban keluarga

Skizofrenia

Keluarga

\section{A B S TR A C T / A B S TR A K}

Schizophrenia is a set of some clinical indications shown by cognitive disorder, emotional disorder, perceptional and behavioural disorder. Schizophrenia does not only attack psychologically but also affects one's social and economic condition. One of the social supports from family is instrumental support as economic function and health treatment given by a family member. Schizophrenia does not directly cause death, but it will make the patient unproductive and become the family burden. Family is the smallest unit of society consisting of the head of the family and some people under the same roof who depends on each other. This research objective is to find out the correlation between instrumental support and burden of schizophrenia family members at Mental Treatment Polyclinic of Grhasia Mental Hospital, Yogyakarta Special Province The design of this research is non-experimental correlation using crosssectional design, while the sampling of the technique was using accidental sampling. The samples of the research consist of the 91 family members of schizophrenia patients at Grhasia Mental Hospital of Jogjakarta Special Province. The data were collected using a questionnaire and then tested statistically using Spearman's correlation. Most of the family instrumental support is in high category (76.1\%), and the burden of the family members of schizophrenia patients is also high (54.9\%). The analysis result shows that there is no significant correlation between instrumental support and burden of family members ( $p$-value $=0.820)$. There is no correlation between instrumental support and burden among the family members of schizophrenia patients at Mental Treatment Polyclinic of Grhasia Hospital Yogyakarta Special Province. It is suggested that the family members of the patients can accept patients well through patient treatment involving all family members, not only caregivers.

Skizofrenia merupakan kumpulan dari beberapa gejala klinis yang penderitanya akan mengalami gangguan dalam kognitif, emosional, persepsi serta gangguan dalam tingkah laku. Skizofrenia tidak hanya menyerang secara psikologis tetapi bisa berdampak ke sosial ekonomi seseorang dan keluarganya. Salah satu dukungan sosial keluarga adalah dukungan instrumental keluarga merupakan fungsi ekonomi 
dan perawatan kesehatan yang diterapkan keluarga
terhadap anggota keluarga. Skizofrenia tidak menyebabkan
kematian secara langsung namun akan menyebabkan
penderita menjadi tidak produktif dan menimbulkan beban
bagi keluarga. Keluarga adalah unit terkecil dari masyarakat
yang terdiri dari kepala keluarga, dan beberapa orang yang
berkumpul dan tinggal disuatu tempat di bawah satu atap
dalam keadaan saling bergantung. Penelitian ini bertujuan
untuk mengetahui hubungan antara dukungan instrumental
dengan beban pada anggota keluarga skizofrenia di Poli
Klinik Keperawatan Jiwa RSJ Grhasia Provinsi DIY. Desain
penelitian ini adalah korelasi non experimental dengan
rancangan penelitian cross sectional, teknik pengambilan
sampel menggunakan accidental sampling. Sampel
penelitian adalah anggota keluarga skizofrenia di RSJ
Grhasia Provinsi DIY yaitu sebanyak 91 responden yang
memenuhi kriteria. Data yang dikumpulkan menggunakan
kuesioner diuji statistik dengan menggunakan Spearman's
correlation. Sebagian besar dukungan instrumental keluarga
dalam kategori tinggi (76,1\%) sedangkan beban anggota
keluara skizofrenia dalam kategori tinggi (54,9\%). Hasil
analisis menunjukkan bahwa tidak ada hubungan yang
signifikansi antara dukungan instrumental dengan beban
pada anggota keluarga ( $(p$ value=0,820). Tidak ada
hubungan dukungan instrumental keluarga dengan beban
pada anggota keluaraga skizofrenia di Poli Klinik
Keperawatan Jiwa RSJ Grhasia Provinsi DIY. Saran kepada
keluarga pasien agar dapat menerima pasien dengan baik
dengan perawatan pasien melibatkan semua keluarga
bukan hanya caregiver.

Copyright (C) 2019 Caring : Jurnal Keperawatan. All rights reserved

\section{${ }^{*}$ Corresponding Author:}

Rohana Fatma Zahra,

Program Studi IImu Keperawatan FKIK Universitas Muhammadiyah Yogyakarta,

Jln. Brawijaya, Geblagan, Tamantirto, Kasihan, Bantul, D I Yogyakarta

\section{PENDAHULUAN}

Masalah gangguan jiwa diseluruh dunia sudah menjadi masalah yang serius, sekitar 450 juta jiwa mengalami dampak dari permasalahan jiwa, saraf, maupun perilaku yang jumlahnya terus meningkat (WHO, 2012). Data riset kesehatan dasar (Riskesdas) tahun 2013 menyebutkan prevalensi gangguan jiwa berat (skizofrenia) pada penduduk di Indonesia 1,7 per mil (Depkes, 2013). Diperkirakan ada sekitar 220 juta penduduk Indonesia mengalami masalah gangguan jiwa dan ada sekitar 20 juta atau $22 \%$ mengidap gangguan kejiwaan dari tingkat ringan hingga berat (Hawari, 2009).

Menurut Riset Kesehatan Dasar (Riskesdas, 2013) Provinsi Yogyakarta angka skizofrenia paling tertinggi, Kasus gangguan kesehatan jiwa berat (Skizofrenia) di Kota Yogyakarta ada sebanyak 2,7 \% per mil, sedangkan angka skizofrenia di Rumah Sakit Jiwa Grhasia Yogyakarta pada bulan Oktober 2015 sebanyak 1.012 orang.

Gangguan jiwa adalah kumpulan-kumpulan keadaan yang tidak normal baik secara fisik ataupun mental, salah satu gangguan jiwa tersebut adalah Skizofrenia. Skizofrenia merupakan suatu gangguan jiwa berat yang menimbulkan efek merusak pada kehidupan penderita maupun anggota keluarganya. Gangguan ini dapat mengganggu persepsi, pikiran, pembicaraan, dan gerakan seseorang, dan nyaris semua aspek sehari-harinya merupakan kumpulan dari beberapa gejala terganggu (Durand \& Barlow, 2007).

Skizofrenia klinis yang penderitanya akan mengalami gangguan dalam kognitif, emosional, persepsi serta gangguan dalam tingkah laku. Penderita gangguan jiwa 
skizofrenia akan mengalami gejala gangguan persepsi, seperti waham dan halusinasi (Kaplan \& Sadock, 2007).

Dukungan keluarga adalah sikap, tindakan, dan penerimaan keluarga terhadap penderita yang sakit. Anggota keluarga memandang bahwa orang yang bersifat mendukung selalu siap memberikan pertolongan dan bantuan jika diperlukan (Nadeak, 2010).

Menurut Kaplan (2001) salah satu dukungan keluarga yaitu dukungan instrumental, dukungan instrumental berupa bantuan langsung seperti materi, tenaga dan sarana. Berisi tentang pemberian perhatian dan pelayanan dari orang lain. Manfaatnya adalah dapat mendukung pulihnya energi dan semangat yang menurun. Dampak diberikannya dukungan instrumental individu akan merasa bahwa masih ada perhatian atau kepedulian terhadap kesusahan yang dialami (Susanti \& Sulistyarini, 2013).

Beban keluarga adalah beban yang dialami oleh keluarga dalam merawat anggota keluarga yang sakit (Wilson \& Kneisl, 1998). jenis yaitu:

Menurut WHO (2008), mengkategorikan beban keluarga dibagi ke dalam dua

a. Beban obyektif, merupakan yang berhubungan dengan masalah dan pengalaman anggota keluarga, terbatasnya hubungan sosial dan aktivitas kerja, kesulitan finansial dan dampak negatif terhadap kesehatan fisik anggota keluarganya

b. Beban subyektif, merupakan beban yang berhubungan dengan reaksi psikolog anggota keluarga meliputi perasaan kehilangan, kesedihan, kecemasan, dan malu dalam situasi sosial, koping, stress terhadap perilaku dan frustasi yang disebabkan karena perubahan hubungan.

\section{BAHAN DAN METODOLOGI PENELITIAN}

Penelitian ini merupakan jenis penelitian korelasi non eksperimental dengan rancangan penelitian cross sectional. Rancangan penelitian cross sectional merupakan pengumpulan data variabel sebab atau risiko dan variabel akibat atau kasus yang terjadi pada objek penelitian dengan diukur atau dikumpulkan secara simultan atau dalam waktu bersamaan (Notoatmodjo, 2012).

Populasi adalah subyek yang memenuhi kriteria yang ditetapkan Populasi dari penelitian ini adalah keluarga yang memiliki anggota keluarga skizofrenia yang berkunjung ke poli klinik keperawatan jiwa RSJ Grhasia Provinsi DIY. Jumlah populasi pada penelitian ini dilihat dari jumlah kunjungan pasien skizofrenia dalam satu bulan yaitu pada bulan Oktober 2015 berjumlah 1.012 pasien yang didampingi keluarga. Teknik dalam penelitian ini adalah accidental sampling.

Dukungan instrumental dan beban keluarga diukur dengan menggunakan kuesioner.

\section{HASIL DAN PEMBAHASAN}

a. Karateristik Responden

Diketahui karateristik responden sebagian besar berumur 40-59 tahun sebanyak 34 orang $(45.9 \%)$, jenis kelamin perempuan sebanyak 38 orang $(51,4 \%)$, pekerjaan swasta sebanyak 30 orang (40.5\%), pendidikan terakhir SMU dan SMP sebanyak 25 orang $(25,2 \%)$, dan hubungan dengan pasien adalah ayah/ibu 22 orang (29.7\%). Data Karateristik responden dapat dilihat secara lebih detail pada tabel 4.1 sebagai berikut:

1) Dukungan Instrumental Keluarga

Data dukungan instrumental keluarga dikategorikan menjadi tiga, yaitu rendah, sedang dan tinggi. Diketahui sebagian besar responden memiliki dukungan instrumental kategori tinggi yaitu sebanyak 70 orang $(76,1 \%)$. 
Tabel 1. Distribusi Frekuensi Responden Berdasarkan Dukungan Instrumental Keluarga di Poli Klinik Keperawatan Jiwa RSJ Grhasia Provinsi DIY, pada bulan Mei 2016

\begin{tabular}{ccc}
\hline $\begin{array}{c}\text { Dukungan } \\
\text { Instrumental Keluarga }\end{array}$ & Frekuensi (f) & Persentase (\%) \\
\hline Sedang & 21 & \\
\hline Tinggi & 70 & 23,1 \\
\hline Total & 91 & 76,1 \\
\hline
\end{tabular}

Sumber: Data Primer (2016)

2) Beban Keluarga

Data beban keluarga dikategorikan menjadi tiga, yaitu rendah, sedang dan tinggi. Diketahui sebagian besar responden memiliki beban kategori tinggi yaitu sebanyak 50 orang $(54,9 \%)$.

Tabel 2. Distribusi Frekuensi Responden Berdasarkan Beban Keluarga di Poli Klinik Keperawatan Jiwa RSJ Grhasia Provinsi DIY, pada bulan Mei 2016.

\begin{tabular}{ccc}
\hline Beban Keluarga & Frekuensi (f) & Persentase (\%) \\
\hline Sedang & 41 & 45,1 \\
Tinggi & 50 & 54,9 \\
\hline Total & 91 & 100 \\
\hline
\end{tabular}

Sumber: Data Primer (2016)

b. Hasil Analisis Bivariat

Analisis bivariat dalam penelitian ini digunakan untuk mengetahui hubungan dukungan instrumental keluarga dengan beban keluarga pada anggota keluarga yang mengalami gangguan jiwa di Poli Klinik Keperawatan Jiwa RSJ Grhasia Provinsi DIY.

Diketahui sebagian besar responden yang memiliki dukungan instrumental sebanyak 70 orang $(76,1 \%)$. Responden beban keluarga 50 orang $(54,9 \%)$.

Tabel 3. Hubungan Dukungan Instrumental Dengan Beban Pada Anggota Keluarga Skizofrenia Di Poli Klinik Keperawatan Jiwa RSJ Grhasia Provinsi DIY, bulan Mei 2016.

\begin{tabular}{cccccccc}
\hline \multirow{2}{*}{$\begin{array}{c}\text { Dukungan } \\
\text { Instrumental } \\
\text { keluarga }\end{array}$} & \multicolumn{6}{c}{ Sedang } & \multicolumn{4}{c}{ Tinggi } & \multicolumn{2}{c}{ Total } & \multirow{2}{*}{ p-value } \\
\cline { 2 - 6 } & $\mathbf{f}$ & $\%$ & $\mathbf{f}$ & $\%$ & $\mathbf{f}$ & $\%$ & \\
\hline Sedang & 9 & 42,9 & 12 & 57,1 & 21 & 100 & \\
Tinggi & 32 & 45,7 & 38 & 54,3 & 70 & 100 & \multirow{2}{*}{0,820} \\
\hline Total & 41 & 45,1 & 50 & 54,9 & 91 & 100 & \\
\hline Sumber: Data Primer (2016) & & & & & &
\end{tabular}

Pembuktian hipotesis penelitian dilakukan dengan Rank Spearman. Berdasarkan hasil analisis Rank Spearman diperoleh nilai dengan $p$ value sebesar 0,820 . Oleh karena nilai $p$-value lebih dari 0,05 ( $p>0,05)$. Ketentuannya yang berlaku adalah $p$-value $>0,05$ maka Ha ditolak dan Ho diterima, sebaliknya apabila nilai $p$-value $<0,05$ maka Ha diterima dan Ho ditolak. Karena nilai $p$-value 0,820 sehingga dapat ditarik kesimpulan tidak ada hubungan dukungan instrumental dengan beban keluarga pada anggota keluarga yang mengalami gangguan jwa di Poli Klinik Keperawatan Jiwa RSJ Grhasia Provinsi DIY.

Berdasarkan hasil penelitian umur responden yang paling banyak adalah 40 tahun - 59 tahun, menurut Erikson (1982) termasuk dalam tugas perkembangan usia dewasa tengah. Tugas perkembangan yang utama pada usia dewasa tengah adalah mencapai generativitas. Generativitas adalah keinginan untuk merawat dan 
membimbing orang lain, mencakup rencana-rencana orang dewasa atas apa yang mereka harap dapat dijadikan guna meninggalkan warisan dirinya sendiri pada generasi selanjutnya.

Karakteristik responden berdasarkan jenis kelamin paling banyak perempuan. $\mathrm{Hal}$ tersebut sejalan dengan teori Ray (2009) bahwa wanita mempunyai sifat penyayang, penyabar, perhatian dan lebih peka terhadap perasaan orang lain. Perempuan cenderung dilukiskan sebagai simbol keanggunan, kelembutan dan terampil.

Menurut Friedman (2010) kondisi dimana anggota keluarga khususnya perempuan, memainkan peranan penting sebagai caregiver primer.

Karateristik responden berdasarkan pekerjaan, sebagian besar adalah swasta. Menurut Walgito (2006) menyatakan bahwa semakin rendah penghasilan seseorang dapat mempengaruhi seseorang untuk memperoleh informasi tentang status kesehatan dan keterbatasan biaya menjangkau fasilitas kesehatan di masyarakat baik media nformasi ataupun pusat pelayanan kesehatan. Selain itu seseorang dengan penghasilan yang rendah lebih mementingkan untuk memenuhi kebutuhan sehari-hari agar bisa bertahan hidup apalagi sudah berkeluarga dan memiliki keturunan.

Hasil penelitian ini diketahui bahwa mayoritas pendidikan responden adalah pendidikan menengah pertama (SMP) dan Sekolah Menengah Atas (SMA). Semakin tinggi pendidikan seseorang semakin mudah pula menerima informasi dan pada akhirnya pengetahuan yang dimilikinya semakin banyak (Notoadmodjo, 2010).

Mayoritas karateristk responden berdasarkan hubungan dengan klien adalah ayah/ibu (orang tua). Peran orang tua sangat penting untuk perawatan keluarga di rumah. Menurut Ali (2009) peran adalah perilaku interpersonal, sifat, dan kegiatan yang berhubungan dengan individu dalam posisi dan satuan tertentu.

Hasil penelitian ini menunjukkan bahwa dukungan instrumental keluarga sebagian besar dalam kategori tinggi. Menurut Nadeak (2010) dalam penelitiannya menyebutkan bahwa dukungan keluarga adalah sikap, tindakan, dan penerimaan keluarga terhadap penderita yang sakit. Anggota keluarga memandang bahwa orang yang bersifat mendukung selalu siap memberikan pertolongan dan bantuan jika diperlukan. Keluarga adalah unit terkecil dari masyarakat yang terdiri dari atas kepala keluarga dan beberapa orang yang berkumpul dan tinggal dalam satu atap dalam keadaan saling bergantung (Setiadi, 2014).

Hasil penelitian menunjukkan bahwa beban yang dialami keluarga sebagian besar kategori tinggi. Hasil penelitian didukung oleh pernyatan Fontaine (2009) menyatakan bahwa beban keluarga adalah tingkat stress keluarga sebagai efek dari kondisi anggota keluarganya. Kondisi ini menyebabkan peningkatan stress emosional dan ekonomi keluarga.

Beban keluarga tinggi dikarenakan dukungan instrumental sangat berpengaruh dalam merespon beban keluarga terutama bersifat beban obyektif, seperti beban financial, pengobatan, bagaimana mencari pelayanan kesehatan jiwa dan cara merawat anggota keluarga (Nuraenah dkk, 2012). Bebagai penelitian menujukkan bahwa salah satu faktor penyebab kambuh gangguan jiwa adalah keluarga yang tidak menangani perilaku klien di rumah, semakin klien sering kambuh keluarga akan sangat terbebani. Oleh karena itu peran serta keluarga dalam proses pemulihan pada klen skizofrenia sangat diperlukan (Keliat, 1996).

Hasil uji statistik menggunakan Spearmank Rank dari hubungan dukungan instrumental keluarga dengan beban pada anggota keluarga yang mengalami skizofrenia di Poli Klinik Keperawatan Jiwa RSJ Grhasia Provinsi DIY didapatkan hasil bahwa tidak terdapat hubungan antara dukungan instrumental dan beban keluarga. 
Penelitian ini tidak sejalan dengan penelitian Nuraenah (2012) yang menyatakan bahwa ada hubungan antara dukungan keluarga dalam merawat anggota keluarga yang sakit. Dukungan instrumental sangat berpengaruh dalam respon beban keluarga seperti mencari pelayanan kesehatan jiwa dalam merawat anggota yang sakit.

Hasil penelitian ini tidak ada hubungannya kemungkinan karena penelitian Nuraenah memberikan dukungan keluarga secara keseluruhan sedangkan penelitian ini hanya memberikan dukungan instrumental keluarga saja. Data karateristik pekerjaan paling banyak adalah Swasta, ini sangat mempengaruhi sosioekonomi keluarga. Semakin tinggi tingkat ekonomi seseorang, maka ia akan lebih cepat tanggap terhadap masalah kesehatan yang dialami oleh dirinya dan keluarganya (Handayani, 2012).

\section{KESIMPULAN}

Karateristik keluarga meliputi usia yang mayoritas berumur 40-59 tahun, jenis kelamin perempuan, pekerjaan swasta, pendidikan terakhir SMU, hubungan dengan pasien ayah/ibu. Dukungan instrumental keluarga yang dialami oleh keluarga paling banyak adalah dukungan instrumental keluarga tinggi. Beban keluarga paling banyak adalah kategori tinggi. Tidak ada hubungan yang signifikan antara hubungan dukungan instrumental dengan beban pada anggota keluarga skizofrenia di poli klinik keperawatan Jiwa RSJ Grhasia Provinsi DIY ( $p=$ value 0,820).

\section{DAFTAR PUSTAKA}

WHO. (2012). Headche disorders. www.Who.int. Diakses tanggal 16 November 2014.

Departemen Kesehatan Republik Indonesia. (2010). Kliping Berita Kesehatan (Mengeren Laju Penderita Gangguan Jiwa). Diakses 7 Desember 2014, dari http://kliping.depkes.go.id/file/7041 Menggerem\%20Laju\%20Penderita\%20Gangguan \%20Jiwa.Pdf.

Hawari, D., (2011), Manajemen stres cemas dan depresi, Jakarta : Balai Penerbit FKUI.

Durand, V., \& Barlow, D.H. (2007). Intisari psikologi abnormal (edisi 4). Terjemahan Yogyakarta: Pustaka Pelajar.

Kaplan, H.I \& Saddock, B.J (2007). Sinopsis Psikiatri Ilmu Pengetahuan Perilaku Psikiatri Klinis. Jilid 1. $10^{\text {th }}$ ed (Terjemahan: Kusuma, W). Jakarta: Bina Rupa Aksara.

Nadeak, R.J (2010). Hubungan dukungan keluarga dengan tingkat kecemasan pasien pre operasi di ruang RB2 RSUPHAM. http//repository.usu.ac.id. (diakses tanggal 21 januari 2014).

Keliat, B. A. (1995). Peran serta keluarga dalam perawatan klien gangguan jiwa. Jakarta : EGC.

Wilson, H.S., and Kneisl, C.R. (1992). Psychiatric nursing. California: Addison-Wesley. Wiguna, T. (2003).

Notoatmodjo. S. (2012). Metodologi penelitian kesehatan. Jakarta: Rineka Cipta.

Ray,S. 2009. Kepribadian wanita di Indonesia. Detik News, p.B.17

Friedman, M.M, Bowden, O \& Jones, M. (2010). Buku ajar keperawatan keluarga: rset, teori, \& praktik. Ahli bahasa, Achir Yani, S. Hamid. [et al.]; editor edisi bahasa Indonesia, Estu Tiar, Ed 5. Jakarta: EGC

Walgito, B. 2004. Pengantar psikologi umum. Yogyakarta: Andi Offset

Ali, Z. 2009. Pengantar keperawatan keluarga. Jakarta : EGC

Setiadi. (2014). Konsep dan Proses Keperawatan Keluarga. Edisi 1. Yogyakarta: Graha IImu.

Fontaine, K. L. (2009). Mental health nursing. New Jersey: Pearson Education Inc 